\title{
THE BLEEDING TIME IN NORMAL AND ABNORMAL SUBJECTS
}

\author{
BY \\ J. R. O'BRIEN \\ From the Pathology Department, The Radcliffe Infirmary, Oxford
}

(RECEIVED FOR PUBLICATION DECEMBER 7, 1950)

The bleeding time is the time between the infliction of a small standard cut in the skin and the moment when bleeding stops. At first sight it would appear that if a subject bleeds excessively from a small cut, he is likely to bleed excessively at operation, and conversely that if a subject bleeds normally from one cut he might be expected to bleed normally from another. But in neither case does the corollary always follow. These occasional failures have led to considerable caution being used in the interpretation of a bleeding time. A further reason for a critical attitude is the comparatively wide and varying limits of normal for this test given in the standard textbooks. This rather unsatisfactory state of affairs has led me to consider the possible causes of the occasional unreliability of this procedure ; it also seemed wise to reinvestigate the variation of the bleeding time in the normal population, and to compare these results with those obtained from patients who were known to have had some type of haemorrhagic incident.

\section{Review of the Literature}

Duke (1910) was the first to make a small incision in the ear and measure the time during which bleeding continued, but he realized that the information derived from this measurement had to be interpreted with care, as he reported that haemophiliacs have normal bleeding times. Ivy, Shapiro, and Melnick (1935) and Ivy, Nelson, and Bucher (1940) were the first to measure accurately the range of normal in man. They appreciated the variation of different incisions in one individual and the importance of capillary contraction in the haemostatic mechanism. In order to test the efficiency of this mechanism more severely, they put a sphygmomanometer cuff on the upper arm inflated to $40 \mathrm{~mm}$. of mercury, and took the mean of the bleeding times obtained from three incisions made on the volar aspect of the forearm. They found that the range of the mean time was 0 to 2.1 minutes. Copley and Lalich (1942) tried to control as many of the variable conditions as possible. They made an incision $6 \mathrm{~mm}$. deep into the pulp of the finger, and put the finger, held on a level with the manubrium sterni, into a saline bath warmed to $37^{\circ} \mathrm{C}$. It is not surprising with this deep incision that the range of their results of a single incision was 0.18 to 5.36 minutes. Dishoeck and Jongkees (1940) considered that the adhesion of the lips of the incision might prevent the escape of blood; they proposed cutting out a saucer-shaped piece of skin and pressing a thin metal plate with a small circular hole in it against the ear so that a part of 
the skin protruded through the hole when it was cut off by a razor slid along the metal plate. They did not give the range of values they observed, but stated that the mean time was 3.24 minutes. The last of the more important normal series in the literature is by Pauwen, Roskam, Derouaux, and Puissant (1942), who based their work on many years of careful and extensive measurements on animals. For humans they recommended that five incisions be made round the lobe of the ear. The mean of these five times-le temps de saignement moyen, 0.42 to 4.42 minutesagreed well with the mean time from the other ear, but they stressed the observation that differences between separate bleeding times in one individual might be considerable, and they also recorded wider variation in the times and a longer mean time for women, and also a slight variation with the age of the subject.

\section{Theory of Bleeding Time Techniques}

There appear to be so many subsidiary factors that may influence the result of the estimation of bleeding time that, quite apart from what may be described as the essential haemostatic mechanism, this type of investigation may quite easily give a misleading answer. The time recorded is the longest time during which any of the incised capillaries continues to bleed. If there are variations between individual capillaries, obviously the more capillaries that are cut, the higher the chances of cutting one or more that bleed for a long time.

The number of capillaries coming to the surface differs in different parts of the body, so the site of the incision will decide the number of capillaries cut. Furthermore, it has proved impossible to standardize accurately the depth of these experimental incisions, so on occasions arterioles and venules must also be cut. However sharp the cutting instrument may be, it must to some extent tear its way through the tissues, a process that on a larger scale often causes almost bloodless lacerations; it appears, therefore, that the sharpness of the instrument will influence the result of this investigation. Once blood has escaped from a blood vessel it has to get out on to the surface of the skin. The elasticity of the skin usually pulls the lips of a linear incision apart, but in old people with inelastic skin the blood may not be able to escape and a small subcutaneous haematoma is formed, and little blood appears on the surface. There are in addition a number of other experimental conditions which may influence the result, such as raising or lowering the venous and capillary blood pressure, the temperature of the skin, and whether it is immersed in a fluid to eliminate the effect of drying.

Lastly, there is the almost philosophical problem of how the normal is defined. The majority of most biometric measurements fall fairly close together, but there are often a few subjects who are within normal limits by all criteria, except that they give a result to this one test that is appreciably different from the majority. Should the normal range extend to include these few measurements, or are these few to be regarded as "abnormal ?" To quote Ryle (1947):

Variability is one of the most distinctive and necessary attributes of life, which admits of no constant and no norm.

\section{Experiments Using the Ivy Technique}

In spite of its apparent theoretical disadvantages, it was necessary to find out if in fact this type of investigation could indicate the presence of a haemorrhagic diathesis. A small scale trial of several methods was first carried out including the routine Ivy tech- 
nique, the result of warming the skin before making an incision, the effect of different types of incision, and the ear-saline technique (Macfarlane, 1946) which consists of pricking the lowest part of the ear and immersing the dependent part in a glass cylinder of saline at $37^{\circ} \mathrm{C}$. so that the blood falls in a thin stream through the saline and the moment when bleeding stops can be accurately read. Inspection of these results showed slight variations between techniques, but even larger differences within each technique, and sometimes large differences in one individual when one type of test was repeated. One apparently normal person continued to bleed for over 15 minutes.

When all these methods were reviewed it became clear that none of them combined painlessness and ease of performance with the advantage of controlling all the subsidiary factors that might effect the bleeding time. For the main series of observations on "normal" people I decided to use the ordinary Ivy technique, partly because it has as many theoretical advantages as any other method except that of Dishoeck and Jongkees, and also because it is one of the methods in general use in this country.

Method.-It was decided to make several estimations of the bleeding time by the chosen method in a number of apparently healthy people with two primary objects in view : first, to observe the variation of the bleeding time in the same individual and from one person to another ; and second, to collect information about, or measure, as many different factors as possible that might influence the bleeding time. It was hoped thereby to be able to estimate from a survey of the whole series the influence, if any, of each of these incidental factors. Every volunteer was accepted, and his or her results included in the series, until a sufficient and approximately equal number of observations had been made on people of all ages and both sexes. A number of people with red hair were specially chosen, because it has been claimed that red-headed people bleed longer than others.

All the subjects accepted were in good general health. Some were laboratory technicians, nurses, labourers, and others were patients who were asked to volunteer so that the possible effect of rest in bed might be investigated. Only those patients with purely local lesions were accepted. The majority had herniae and were tested before operation ; others had local gynaecological abnormalities, or were awaiting plastic surgical treatment.

At the beginning of the interview with each subject a record was made of the age, sex, physical build, hair colour, skin thickness and elasticityv, and his opinion as to whether he bled abnormally from cuts or bruised more than other people. In case there were day-to-day variations in the same individual, each subject was visited twice, usually on consecutive days, to get paired observations. On each occasion a record was made of the time of day, hours after a meal, and the blood pressure at the end of the interview. The forearm skin temperature was roughly measured by a mercury thermometer with a long cylindrical bulb covered by sorbo rubber tightly strapped on the forearm above the wrist.

For the sake of uniformity I carried out all the investigations myself and with the same apparatus. One spring lancet with a blade $2 \mathrm{~mm}$. wide, $0.5 \mathrm{~mm}$. thick, and set at $2.5 \mathrm{~mm}$. depth was used throughout, but it had to be sharpened a number of times. Three incisions were made on the volar aspect of one arm at the first visit, while the other arm was used at the second visit with a manometer cuff on the upper arm inflated to $40 \pm 5 \mathrm{~mm}$. Hg. The incisions were made at five-second intervals. Then each was lightly " blotted" every 15 seconds by sliding the edge of a piece of filter paper slowly over the cut, a separate filter paper being used for each, so that a permanent record was made of the time taken, indicated by the number of blots, and a rough record of the quantity of blood lost. Since bleeding from some of the incisions decreased extremely slowly, it was found impossible to devise any exact definition of the end- 
point. All incisions that continued to bleed were observed for 15 minutes. Observation was then discontinued.

Results.-The results obtained by this method and the two other methods used subsequently are tabulated below (Table I).

TABLE I

Comparison of Results with Three Techniques

\begin{tabular}{|c|c|c|c|c|c|c|c|}
\hline \multirow{2}{*}{\multicolumn{2}{|c|}{ Technique }} & \multirow[t]{2}{*}{ Site } & \multirow{2}{*}{$\begin{array}{c}\text { No. of } \\
\text { Incisions } \\
\text { per } \\
\text { Subject }\end{array}$} & \multirow{2}{*}{$\begin{array}{l}\text { No. of } \\
\text { Subjects }\end{array}$} & \multirow{2}{*}{$\begin{array}{c}\text { Total } \\
\text { No. of } \\
\text { Observa- } \\
\text { tions }\end{array}$} & \multicolumn{2}{|c|}{$\underset{\text { (minutes) }}{\text { Mean Bleeding Time }}$} \\
\hline & & & & & & Average & Range \\
\hline Ivy & .. & Forearm & 6 & 98 & 588 & $\begin{array}{l}\text { ô } 5 \cdot 0 \\
\text { q } 6.5\end{array}$ & $\begin{array}{l}1 \cdot 8-10 \cdot 0 \\
1 \cdot 3-10 \cdot 5\end{array}$ \\
\hline Ear-saline & . & Ear & 2 & 60 & 120 & 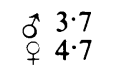 & $\begin{array}{l}2 \cdot 0-100 \\
2 \cdot 0-12 \cdot 0\end{array}$ \\
\hline Duke & .. & Ear & 2 & 67 & 134 & $\begin{array}{l}0_{1} 4 \cdot 2 \\
\Varangle 5 \cdot 6\end{array}$ & $\begin{array}{r}0-6 \cdot 5 \\
0 \cdot 5-10 \cdot 1\end{array}$ \\
\hline \multicolumn{3}{|c|}{ Combined totals } & & 225 & 842 & $5 \cdot 06$ & $0-12 \cdot 0$ \\
\hline
\end{tabular}

$\hat{\jmath}=$ Males. $q=$ Females.

The most impressive result was that this method in the present series gave isolated bleeding times from 0 up to $15+$ minutes, i.e., blood was flowing freely at the end of 15 minutes, whereupon the observation was discontinued. For the statistical analysis and for the purpose of working out the mean bleeding times these $15+$ minute readings have been taken as 15 minutes exactly ; this is obviously incorrect, but no fairer way of analysing these results could be devised. As far as can be judged, the effect of this assumption is likely to be small, and would only make interpretation difficult in borderline cases. In the ensuing analysis the findings are all either definitely significant, or quite insignificant, so that this technical point is fortunately unimportant. There was so much variation in the results within individuals that it was apparent that only statistical analysis would reveal any slight differences within the group of observations as a whole.

Fig. $1^{*}$ shows the general pattern of distribution, with a fairly large number of observations of 0 minutes (i.e., no bleeding observed) even though a reasonable incision had been made. The histogram shows that there is a high peak of frequency of observations between three and six minutes and that there is a very long tail to the right where the curve appears to become asymptotic: in other words, a few subjects had some very long bleeding times. Fig. 2, in which the means of all six readings for each subject are recorded, shows much the same distribution except that there is not such a wide scatter along the time scale, which signifies that the very long and the very short bleeding times were cancelled out by intermediate results.

Inspection of the results shows that females tend to have longer bleeding times than males. This observation is supported by the difference in the mean bleeding

* In all the histograms where an arrow is used it indicates the dividing line between $95 \%$ of the observations and the $5 \%$ of observations which had the longest times. 


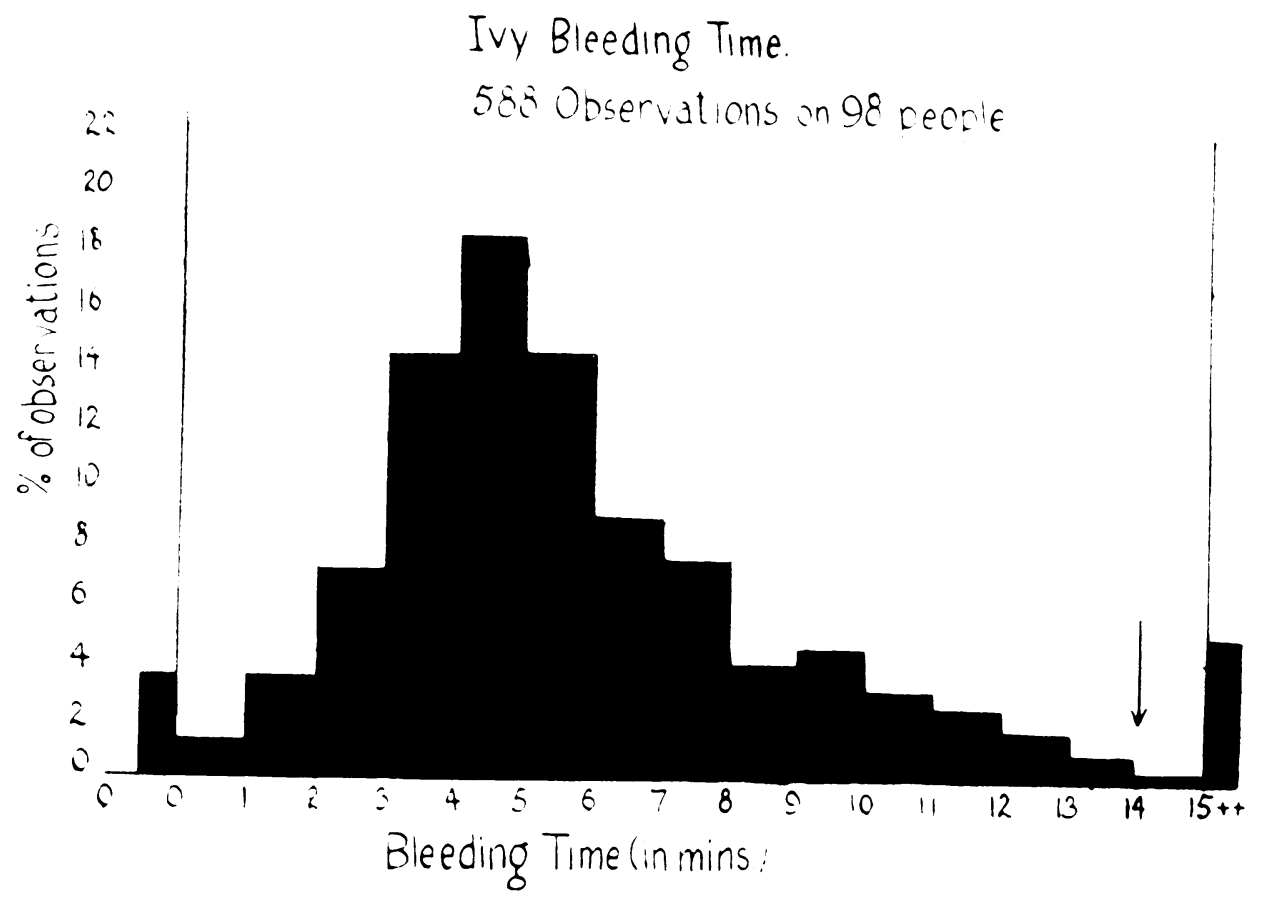

FIG. 1

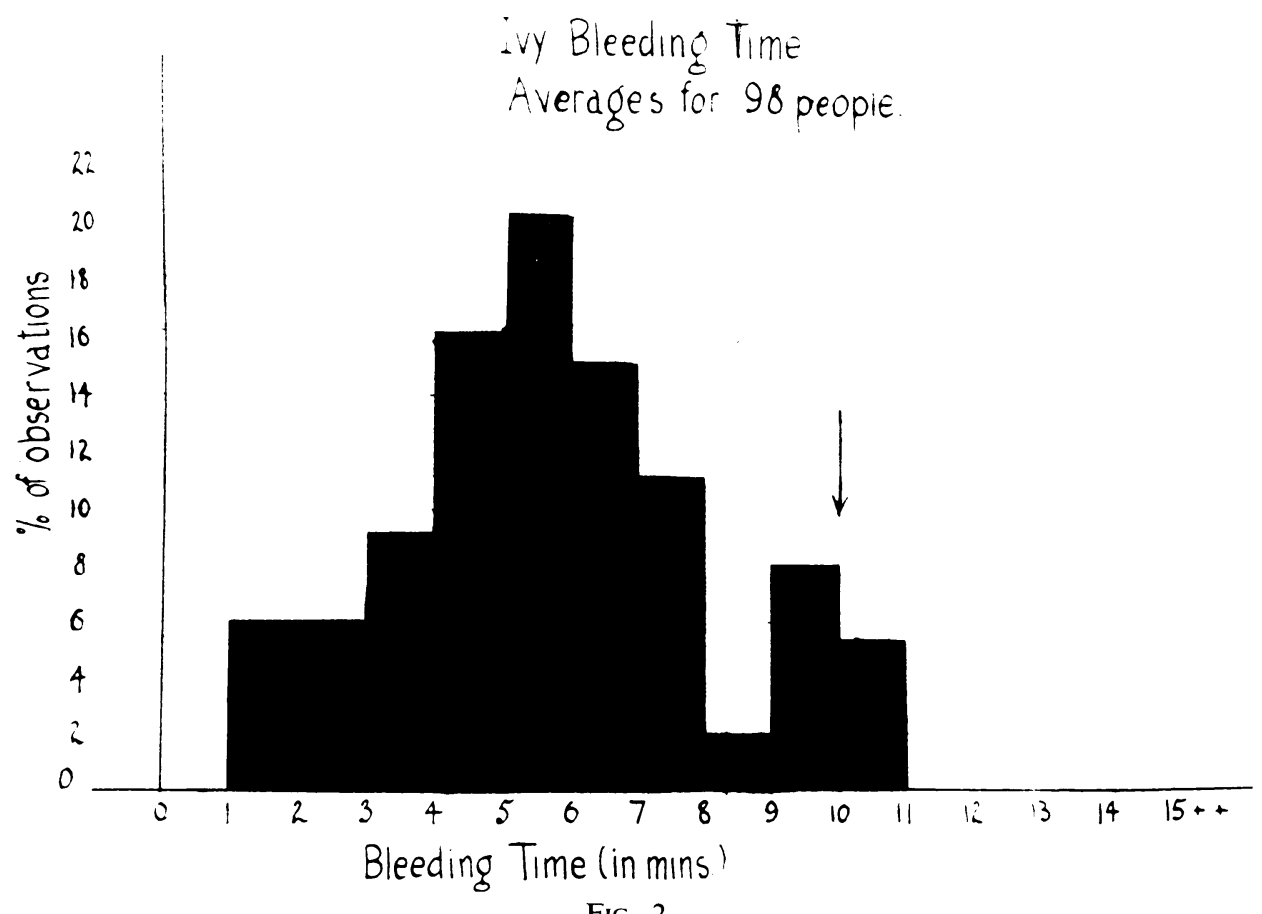

FIG. 2 
time for all males compared with that for all females (Table I and Fig. 3). Any further differences were obscured by the wide variation within the individual so results were submitted to the usual statistical analysis of variance (Table II).* The preliminary analysis shows that there is a significantly greater degree of variation of the bleeding times between different subjects when compared with the variation within the individual subjects; in other words there is more variation between results on different subjects than occurs between readings on the same subject. Because of the marked sex difference all future analyses have been divided into two, one for each sex.

The second analysis carries the procedure of the first into more detail by subdivision of the two basic comparisons. First, the general comparison between patients may be regarded as composed of three distinct elements: between sexes, between male patients, and between female patients. Separate variance estimates can be derived from each of these three comparisons. Similarly it is possible to subdivide the general comparison "within patients." Three of the readings on each patient were taken at one time, three at another. Thus for each sex separately one variance estimate may be derived from a comparison of the mean bleeding times

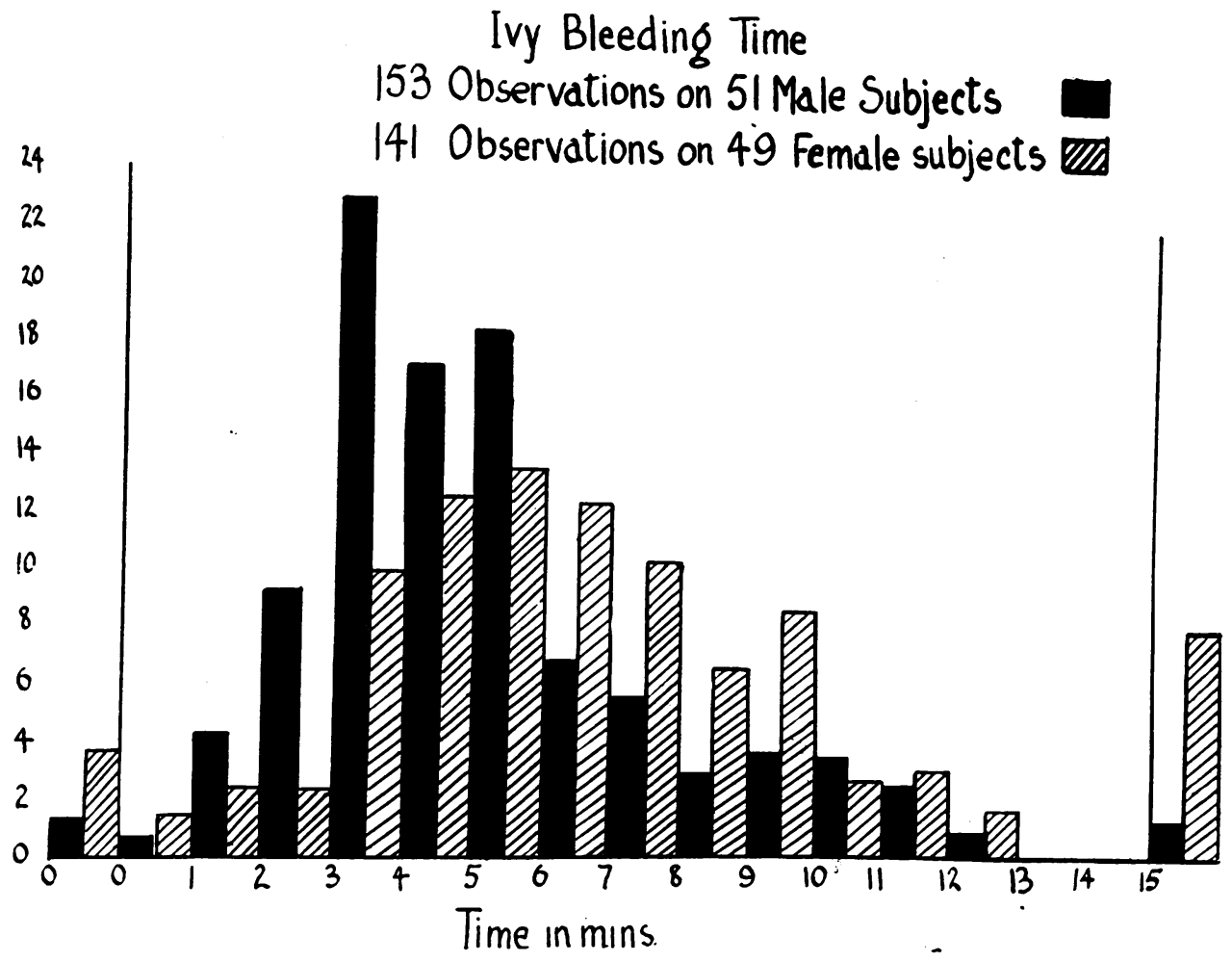

FIG. 3

* The statistical analysis was supervised and largely carried out by Mr. I. Sutherland, of the Nuffield Department of Social Medicine. 
TABLE II

ANALYSES OF VARIANCE

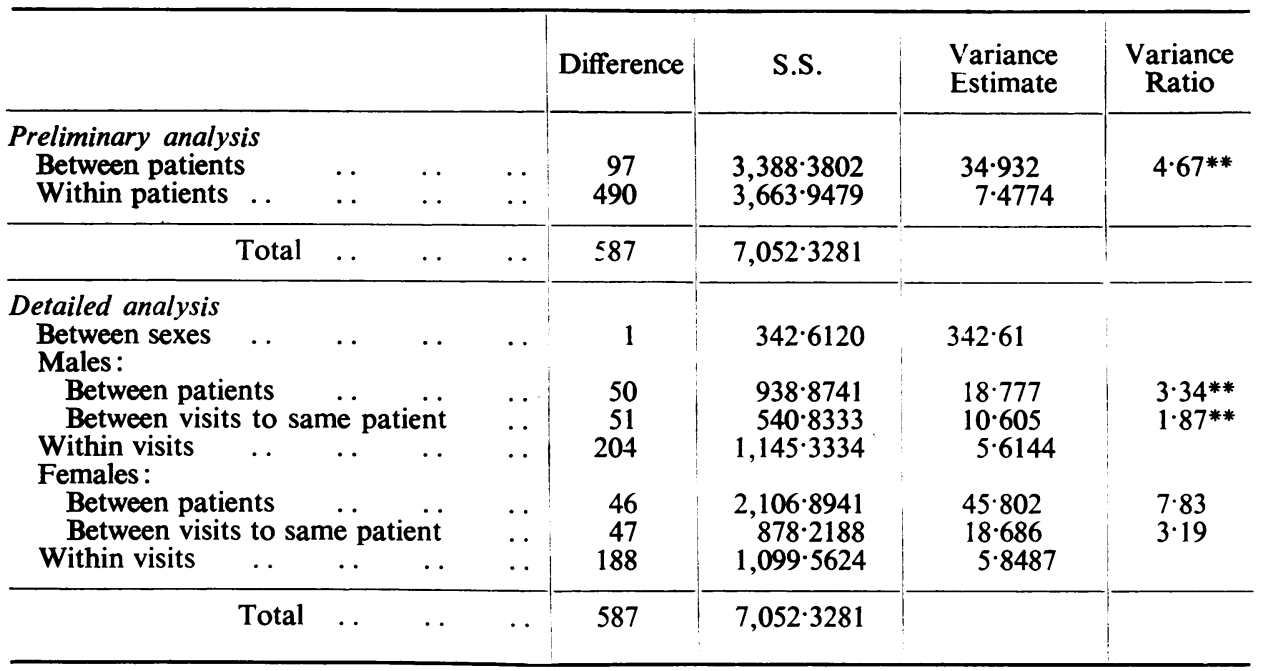

Variance ratios: (a) Sex difference:
$\frac{342 \cdot 61}{18.777}=18 \cdot 25 * *$
$\frac{342 \cdot 61}{45 \cdot 802}=7 \cdot 48^{* *}$
(b) Males:
$\frac{18 \cdot 777}{10 \cdot 605}=1 \cdot 77^{*}$;
$\frac{10 \cdot 605}{5 \cdot 614}=1.89 * *$
(c) Females:
$\frac{45 \cdot 802}{18 \cdot 686}=2 \cdot 45^{* *}$;
$\frac{18 \cdot 686}{5 \cdot 8487}=3 \cdot 19^{* *}$

\begin{tabular}{|c|c|c|c|c|}
\hline & Difference & S.S. & $\begin{array}{l}\text { Variance } \\
\text { Estimated }\end{array}$ & $\begin{array}{l}\text { Variance } \\
\text { Ratio }\end{array}$ \\
\hline $\begin{array}{l}\text { Linear Regression on Age } \\
\text { Males: }\end{array}$ & & & & \\
\hline $\begin{array}{l}\text { Linear regression } \\
\text { Other differences between patients } \\
\text { Females: }\end{array}$ & $\begin{array}{r}1 \\
49\end{array}$ & $\begin{array}{r}45 \cdot 9643 \\
892 \cdot 9098\end{array}$ & $\left.\begin{array}{l}45 \cdot 964 \\
18 \cdot 223\end{array}\right\}$ & $2 \cdot 52$ \\
\hline $\begin{array}{l}\text { Linear regression } \\
\text { Other differences between patients }\end{array}$ & $\begin{array}{r}1 \\
45\end{array}$ & $\begin{array}{r}13 \cdot 8106 \\
2,093 \cdot 0835\end{array}$ & $\left.\begin{array}{l}13 \cdot 811\} \\
46 \cdot 513\end{array}\right\}$ & $1: 3 \cdot 37$ \\
\hline
\end{tabular}

of the same patient on two different occasions, and another from the variation in readings on the same patient at the same time. This leads to four more estimates, giving a total of seven in the detailed analysis. Any two of these estimates may be compared.

The findings may be summarized as follows. (1) There is a significant sexdifference in bleeding time; females have a longer bleeding time at all ages. (2) The 
subject's bleeding time varies significantly from time to time. (3) There are "constitutional " differences between patients which are not obscured by the "temporal" variation just mentioned. (4) There is no evidence that the constitutional differences are connected with age, hair-colour, physical constitution, skin thickness, skin elasticity, or skin temperature.

\section{Series Using the Ear-Saline Technique}

The results obtained by the Ivy technique do not agree with those of Ivy's own series, and some remarkably long bleeding times were recorded, due presumably in part to the fact that I must have made a larger incision. It was accordingly decided to measure the bleeding times of healthy people obtained by two other techniques. The second method was that suggested by Macfarlane (1946). I thought it wise to use a different site, and the control of temperature and drying appeared to be the advantages of this method. For the third series I chose the Duke method (1910), which is perhaps the most commonly used.

The method for the ear-saline technique has already been described and in this series I made a single incision in one ear and measured the bleeding time and immediately repeated the procedure on the other ear. No questionary was filled in, the sex and age being the only facts noted.

Results. - A histogram (Fig. 4) of the individual observations is essentially similar to those obtained by the Ivy technique, but it will be seen that no cuts failed to bleed, while three out of 120 incisions bled for over 15 minutes. A higher percentage of observations falls close to the mean, which is considerably shorter than with the Ivy technique (Table I) and $66.5 \%$ of the readings fall between one and five minutes.

Statistical analysis confirms that there is a significantly greater variation between patients compared with the variation between the two ears, and the sex difference is maintained.

\section{Series Using the Duke Technique}

For this series the puncture made by the spring lancet was modified, in accordance with Duke's original suggestion that an incision be made of sufficient size to produce blots on the blotting paper about $1 \mathrm{~cm}$. in diameter.

Method.-The cleaned ear was lightly pricked on the anterior surface of the lobe and the issuing blood blotted every half minute from the bottom of the lobe, so that the wound was never disturbed. The second ear was pricked 15 seconds later, and the two bleeding times were estimated simultaneously. The moment at which bleeding stopped was more difficult to determine than in either of the two other methods.

Results.-A histogram (Fig. 5) of the individual results shows a fairly larte number of zero readings. These were because the wound did not bleed, and not because it could not bleed, since it was confirmed that most of these incisions would bleed if the skin was gently stretched. It will be noted that no single observation continued for more than twelve and a half minutes. It is not known whether this was due to the smallness of the sample examined, to the slightly smaller puncture, or to other differences in technique. Essentially, however, this curve is similar to the others. 


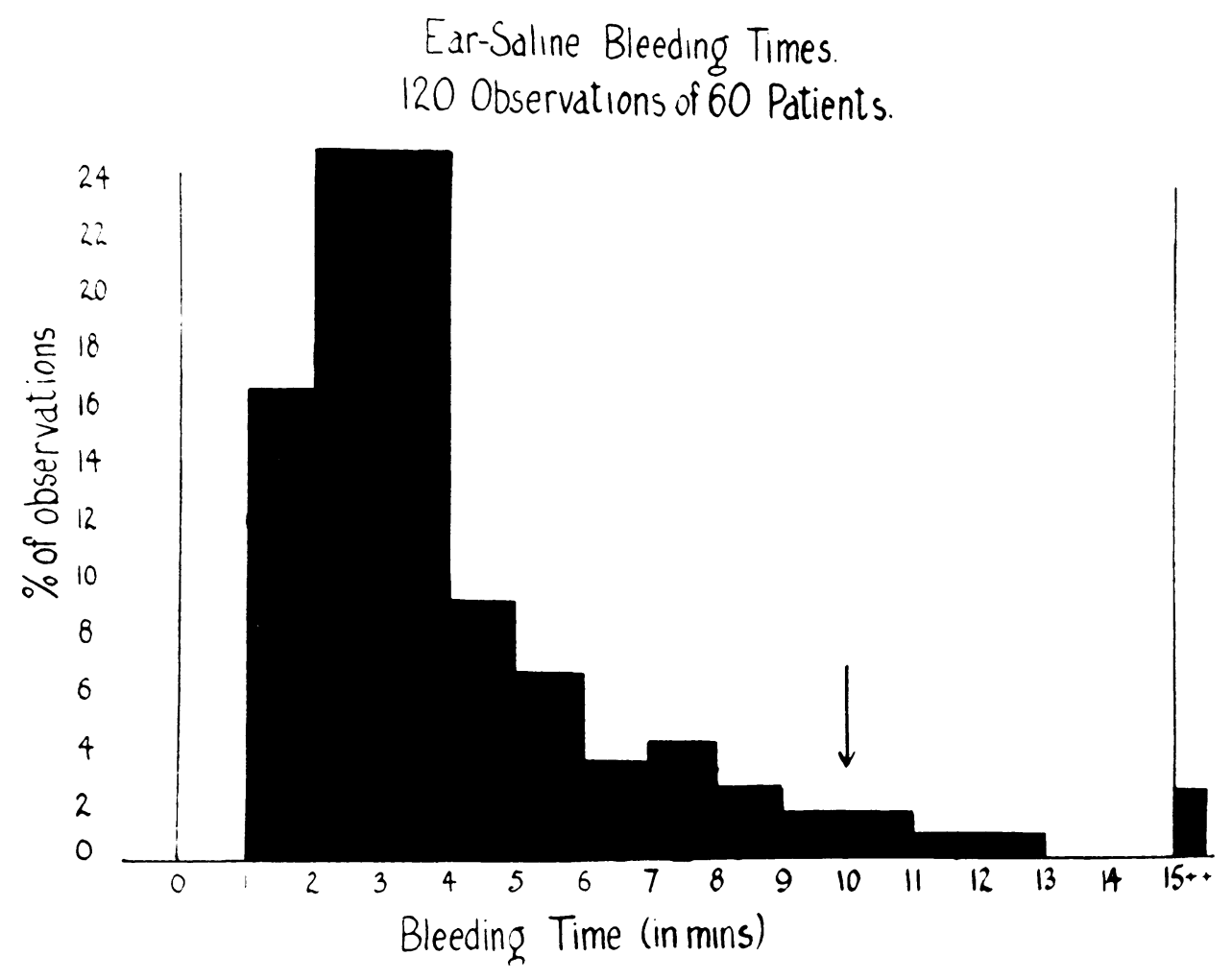

FIG. 4

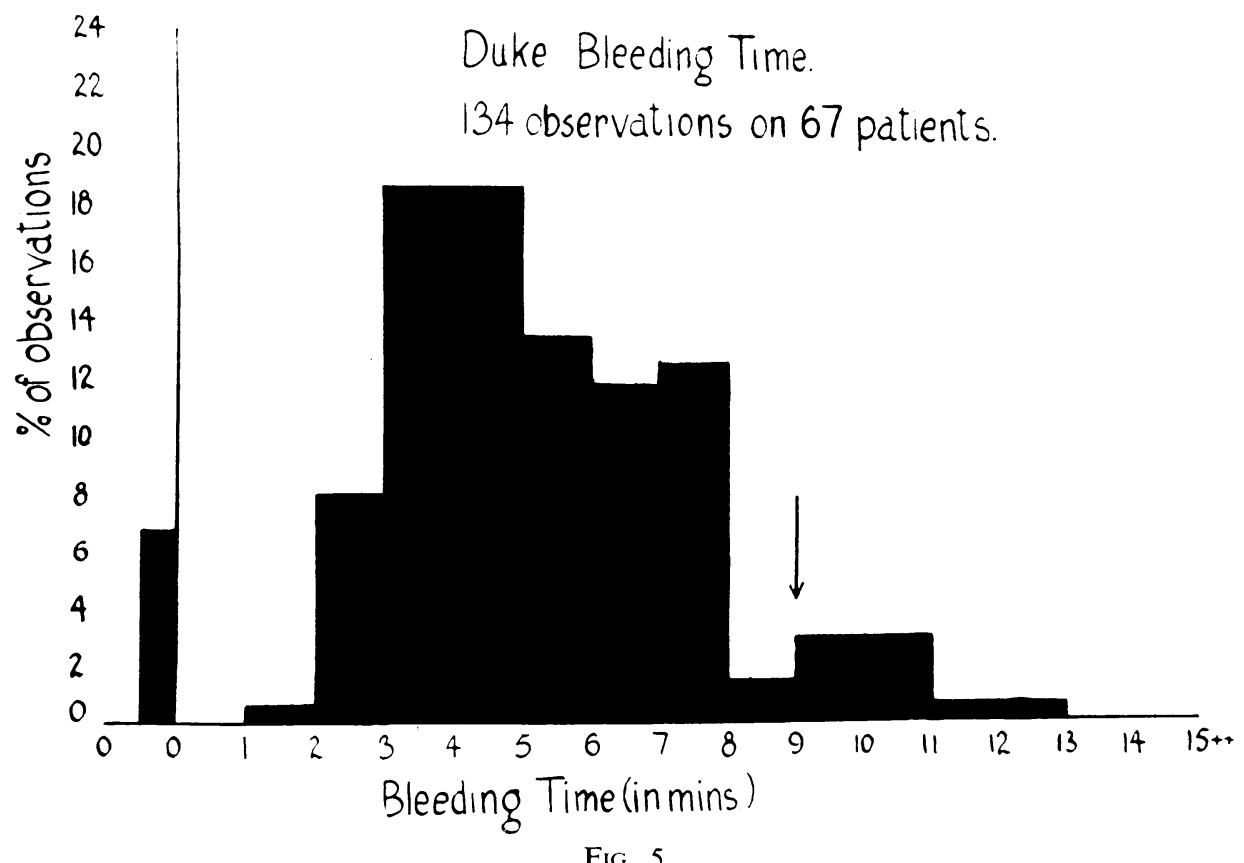

FIG. 5 


\section{The Three Techniques Compared}

A composite histogram (Fig. 6) of the three techniques shows a very similar distribution of results. The mean time is shortest by the ear-saline time, and longest by the Ivy technique; the long tail to the right is obvious in each series.

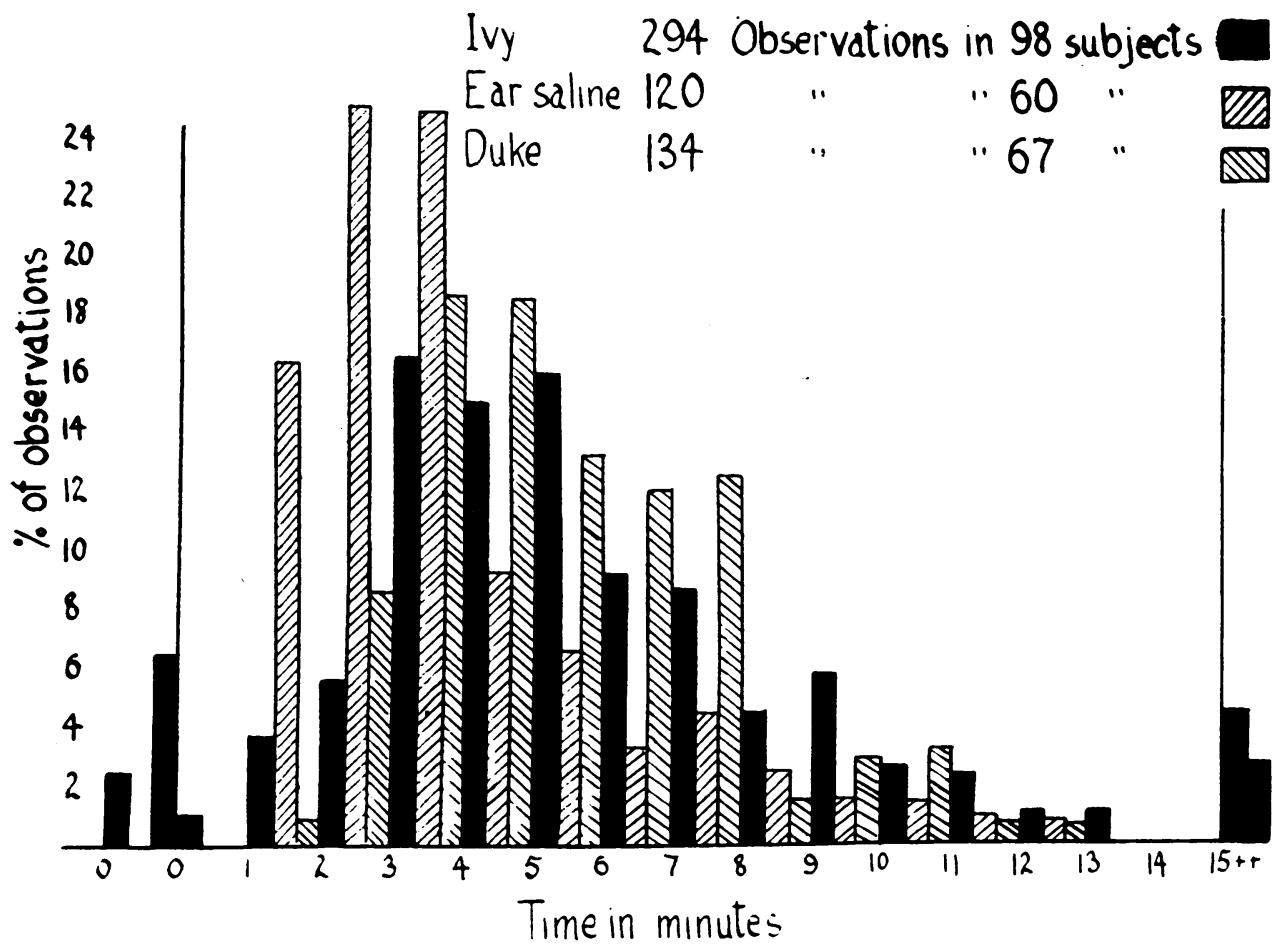

FIG. 6

Nine male and nine female subjects had volunteered for all three series, and these results were tabulated and subjected to statistical analysis. Again there is significantly greater variation between patients and between different visits to the same patient than there is variation within patients at one visit. There is no significant variation between techniques that cannot be accounted for by the two factors just mentioned.

\section{The Bleeding Time of Abnormal Patients}

The results of all the bleeding times carried out as part of the routine of the Pathological Laboratory of the Radcliffe Infirmary during two years will now be reported. These results were obtained by a number of technicians using different instruments, but they all used the Ivy technique and usually made three incisions. For most of these patients the laconic diagnosis on the pathological request form was accepted ; in a number of patients, particularly those with long bleeding times, the diagnosis was confirmed from the case notes. In all cases, however (even in those with no diagnosis given on the request form), it may confidently be assumed 
that the doctor who asked for the investigation thought that there was or might be something wrong with the patient's haemostatic mechanism.

The results of 278 bleeding times, almost all of which are the mean of three observations, were available for study. They were arbitrarily divided into two groups, first, those from patients with more than 100,000 platelets per ml., and secondly those with severe thrombocytopenia and cne case of congenital athrombocytopenic purpura. Two hundred and five bleeding times were available from patients with many platelets, and the diagnoses are summarized in Table III.

TABLE III

Diagnosis of Patients with more than 100,000 Platelets Per ml.

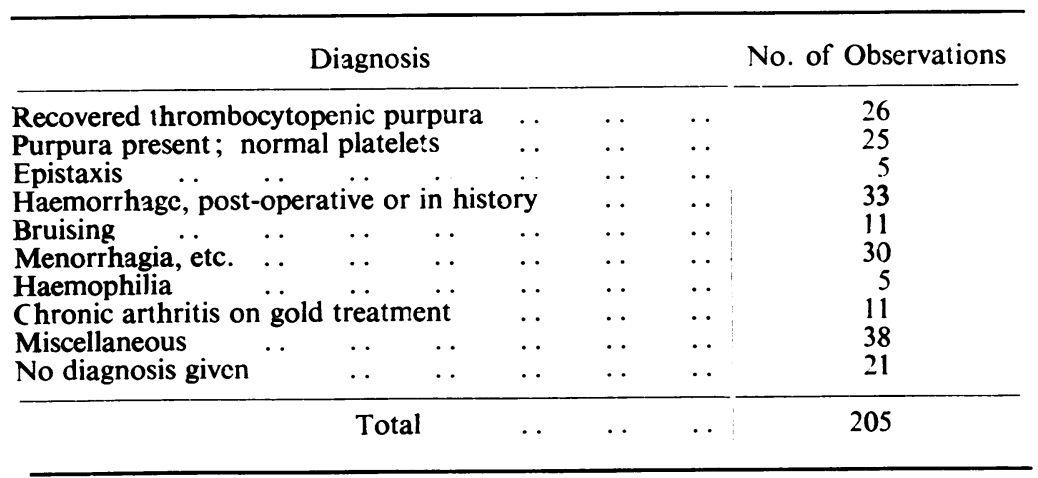

Each group of results was examined separately and did not differ significantly from the others so that the whole 205 results can be represented in the form of a histogram (Fig. 7). It will be seen that this histogram is of exactly the same shape as Figs. 1 and 2 of the 98 normal subjects. The mean for the abnormal patients is 4.46 minutes, and that for normal males and females by the Ivy technique is 5.8 minutes. Since these two histograms are for all practical purposes identical, it is clear that this test does not help to reveal those patients with more than 100,000 platelets per ml. of blood, who bleed excessively at operation or have other haemorrhagic manifestations. In view of the similarity of the histograms of the normal results obtained by the ear-saline and the Duke methods with those obtained by the Ivy method, it is also reasonable to assume that neither of these two methods and probably any of the other recognized methods would have revealed any abnormality in these 205 observations. Furthermore the similarity of these two histograms (Figs. 7 and 2) indicates that it was not some personal variation of the technique which produced the long times, since many technicians carried out the tests on the abnormal patients. It seems therefore that the error of the method due to observer differences are quite insignificant when compared with the variation of the subjects.

The only Radcliffe Infirmary results excluded from consideration above are those from patients with a platelet count below 100,000 per $\mathrm{ml}$. and the one case of athrombocytopenic purpura (Macfarlane, 1941). The diagnoses and numbers of patients and observations are listed in Table IV.

Although the numbers in each group are small, the bleeding times were fairly uniformly long, and I think it is justifiable to draw a histogram of this group as a 
whole (Fig. 8). It will be seen that in addition to $39.7 \%$ of the results continuing for 15 minutes or over, the rest show many more prolonged times (9-14 minutes) than are recorded in the normal population. These last results are, of course, nothing new; it has long been known that thrombocytopenic patients bleed excessively and have a grossly prolonged bleeding time.

TABLE IV

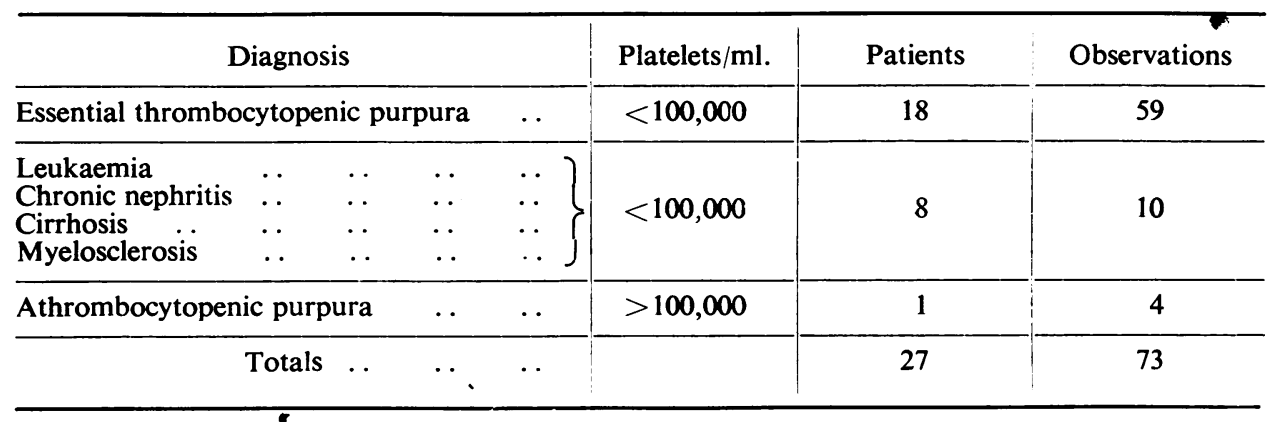

"Abnormal" Patients with $>100,000$ platelets 205 Mean Ivy Bleeding Times

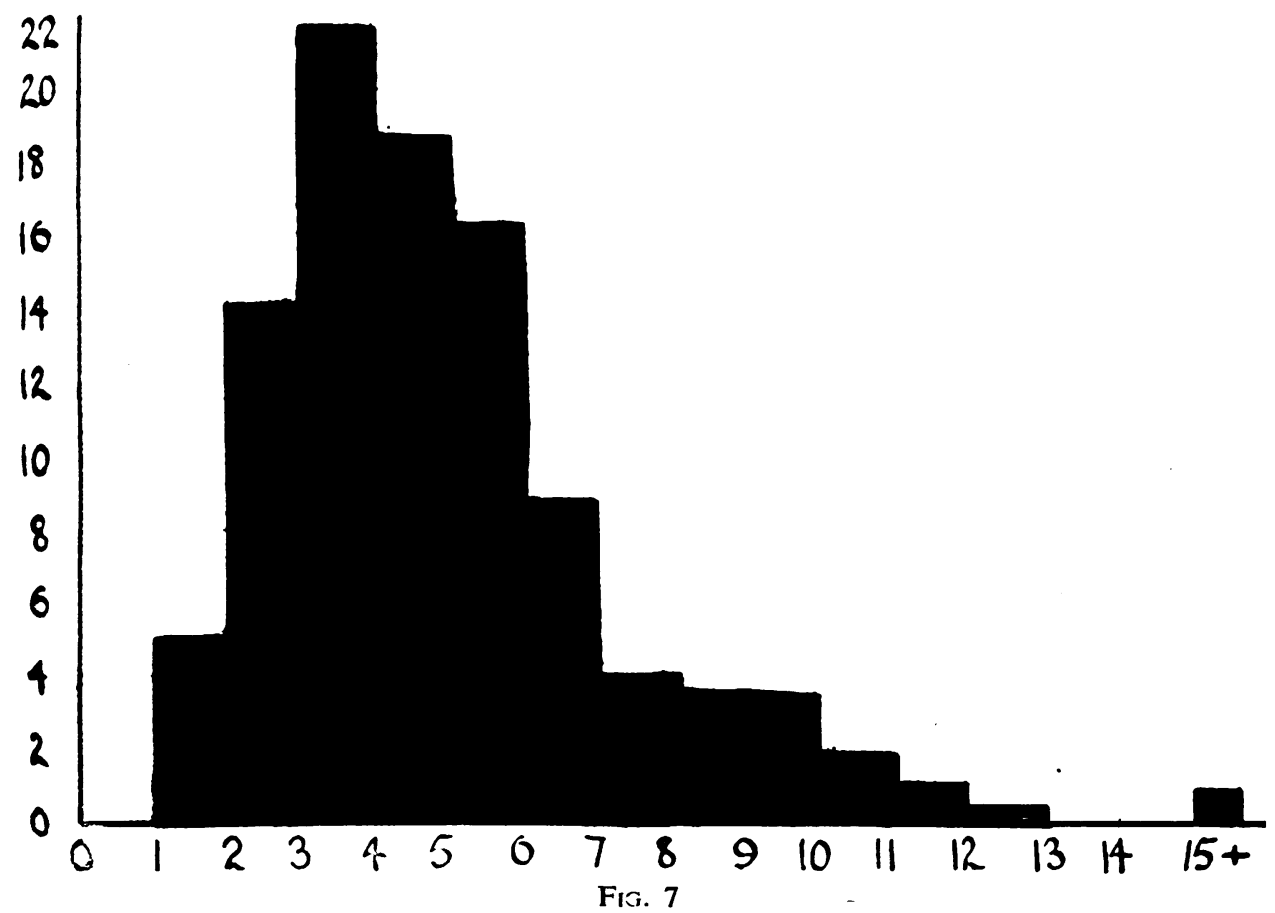




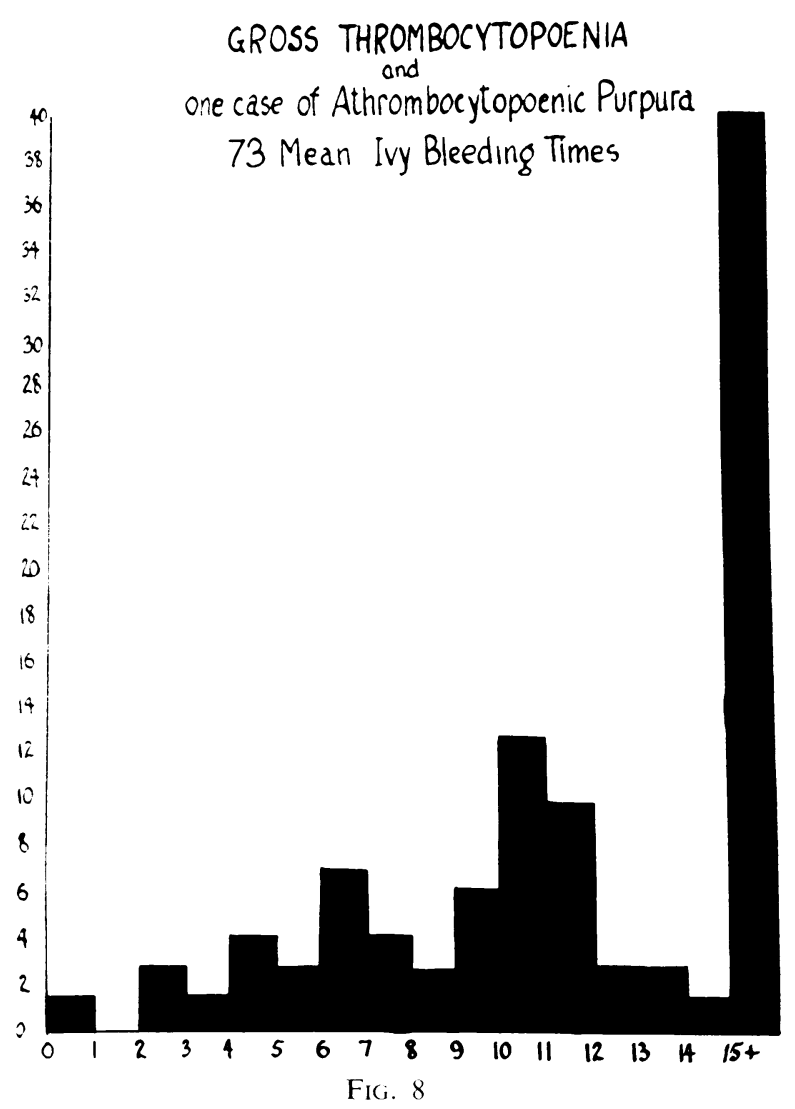

The only patient that must be singled out is the girl with athrombocytopenic purpura who usually had a very long bleeding time and always had normal platelets. It might be argued that this was the only case in which the bleeding time had given information that could not be obtained from counting the platelets. This is true, but in patients like this, and this girl was no exception, there is usually such a definite history of haemorrhagic episodes, that even without a bleeding time, an abnormality of the haemostatic mechanism must be suspected which may be confirmed by estimating the bleeding time. Repeated estimations of the bleeding time are, however, essential in finding minor degrees of this syndrome in members of an afflicted family, who do not have a definite history of bleeding.

\section{Conclusions}

The surgeon has long been asking for a test which will reveal those cases which will bleed excessively at operation, and the physician will often ask for laboratory tests to support a history of easy bruising, purpura, or excessive bleeding from cuts. The results of estimating the bleeding time of all such cases referred to the Pathological Department of the Radcliffe Infirmary during the past two years give no 
more evidence than is obtained from a single platelet count. (Although the error of any method of counting the platelets is large, the critical level of about 100,000 per $\mathrm{ml}$. is so far below the normal level-roughly 300,000 by the method usedthat confusion is not likely to arise from the inaccuracies of this test.) If the platelet count is normal, then it can safely be assumed that the bleeding time also will be "normal"; that is to say it will fall probably between two and six minutes, but may be much longer although it will not repeatedly continue for more than 15 minutes. The only exceptions to this rule are the rare capillary abnormalities like athrombocytopenic purpura, the Ehlers-Danlos syndrome, and congenital telangiectasia, in which syndromes the platelets are present in normal numbers, but the bleeding time may be grossly prolonged if the abnormal capillaries are punctured. As a rule patients with these syndromes give a characteristic history.

We partially understand a few of the component parts of the haemostatic mechanism, but we have so little understanding of the process as a whole that we can only speculate about the cause of the gross variations encountered when estimating the bleeding time in apparently healthy people.

\section{Summary}

Three estimations of the Ivy bleeding time were made on 98 apparently healthy volunteers on two separate occasions. The individual times varied from zero to more than 15 minutes, while the majority of the recorded times were between three and six minutes. Two further series by the Duke method (67 subjects) and the ear-saline method (60 subjects) confirmed these results with only minor differences.

A study was made of the results from all the patients referred to the Pathological Department of the Radcliffe Infirmary, Oxford, during the last two years, who complained of haemorrhagic manifestations. These results were divided into those from patients with over of 100,000 platelets per ml. of blood and, those with gross thrombocytopenia. The bleeding times of the patients with over 100,000 platelets per ml. were indistinguishable from those of the normal controls; the majority of the patients with gross thrombocytopenia had long bleeding times. It is concluded that, except in a few rare diseases, the bleeding time gives no more information than a platelet count.

I should like to acknowledge the great help Dr. R. G. MacFarlane has given me at all stages of this work, without whose encouragement this paper would never have been written; I also have to thank Mr. I. Sutherland, of the Nuffield Department of Social Medicine, for the analysis of variance, and the volunteers for their patience and longsuffering.

\section{REFERENCES}

Copley, A. L., and Lalich, J. J. (1942). J. clin. Invest., 21, 145.

Dishoek, H. A. E., and Jongkees, L. B. W. (1940). Klin. Wschr., 19, 1216.

Duke, W. W. (1910). J. Amer. med. Ass., 55, 1185.

Ivy, A. C., Nelson, D., and Bucher, G. (1940). J. Lab. clin. Med., 26, 1812.

Shapiro, P. F., and Melnick, P. (1935). Surg. Gynec. Obstet., 60, 781.

MacFarlane, R. G.'(1941). Quart. J. Med., n.s. 10, 37, 1.

-- (1946). Personal communication.

Pauwen, L. J., Roskam, J., Derouaux, G., and Puissant, A. (1942). Arch.int. Rharmacodyn., 67, 390. Ryle, J. A. (1947). Lancet, $1,1$. 